Arq. Bras. Med. Vet. Zootec., v.69, n.1, p.198-204, 2017

\title{
Dietas pós-eclosão suplementadas com fontes de gordura e acrescidas de taurina e glicina sobre a morfometria intestinal e o desempenho de frangos de corte de um a 21 dias
}

\author{
[Post-hatch diets supplemented with sources of fat and added taurine and glycine on the intestinal \\ morphology and performance of broilers at 1 to 21 days] \\ J.I.M. Fernandes, A. Rorig, E.T. Gottardo, J.M. Schmidt, A.M. Burin Júnior, L.M. Fülber \\ Universidade Federal do Paraná - UFPR - Palotina, PR
}

\section{RESUMO}

O objetivo deste estudo foi avaliar o efeito do fornecimento de dietas pós-eclosão suplementadas com diferentes fontes de gordura insaturada e adicionadas ou não de taurina e glicina sobre o desempenho produtivo, a biometria e a morfometria do intestino delgado de pintos de corte de um a 21 dias de idade. Foram utilizados 480 pintos de corte machos de um dia de idade da linhagem Cobb. O delineamento foi inteiramente ao acaso, em esquema fatorial $2 \times 4$, com e sem suplementação de taurina e glicina e quatro dietas (controle, óleo de peixe, de soja e de girassol), totalizando oito tratamentos com seis repetições de 10 aves cada. As rações experimentais foram fornecidas de zero a quatro dias de idade. O desempenho zootécnico foi avaliado ao alojamento e aos quatro, sete e 21 dias de idade. Nestas mesmas datas, foram sacrificadas duas aves por unidade experimental para biometria do intestino e histomorfometria da mucosa do intestino. A adição de diferentes fontes de gordura e a suplementação de glicina e taurina às dietas de transição não influenciaram o desempenho produtivo de um a 21 dias. A suplementação das dietas com glicina e taurina alterou a morfologia da mucosa intestinal, principalmente do duodeno, resultando em maior comprimento do vilo e relação vilo:cripta. Entretanto, parte dos efeitos positivos depende do tipo de óleo adicionado, mostrando que dietas pós-eclosão acrescidas de fontes de lipídios podem ser benéficas no desenvolvimento da capacidade funcional do intestino de frangos de corte.

Palavras-chave: sais biliares, lipídios, mucosa intestinal, ganho de peso

\begin{abstract}
The aim of this study was to assess post-hatch diets supplemented with different sources of unsaturated fat and added or not with taurine and glycine on the productive performance, biometry and morphology of small intestine of chicks from 1 to 21 days of age. Four hundred and eighty (480) one day old male broiler Cobb chicks were used. The experimental design was completely randomized in a factorial $2 \times 4$, with and without supplemental taurine and glycine and 4 diets (control, fish, soy and sunflower oil), totaling six treatments with six repetitions of $10 \mathrm{birds}$ each. The experimental diets were supplied from 0 to 4 days old. The performance was evaluated in housing and 4, 7 and 21 days of age. On these same dates, 2 birds per experimental unit were sacrificed for gut biometrics and histomorphometry of intestinal mucosa. The addition of different sources of fat, glycine and taurine supplementation on transition diets did not influence productive performance from 1 to 21 days. Supplementation of diets with glycine and taurine altered the morphology of the intestinal mucosa, mainly of the duodenum, resulting in greater length of villi and villi: crypt ratio. However, the positive effects depend on the type of oil added, showing that post-hatch diets increased with lipid sources may be beneficial in the development of the functional capacity of the intestine of broilers.
\end{abstract}

Keywords: bile salts, lipids, intestinal mucosa, weight gain

Recebido em 21 de Setembro de 2015

Aceito em 13 de junho de 2016

E-mail: jimfernandes@ufpr.br 


\section{INTRODUÇÃO}

O período pós-eclosão é considerado um período de transição entre a vida embrionária e a vida independente, em que as reservas nutricionais provenientes do saco vitelino são consumidas e a ave necessita ingerir alimentos exógenos, visando ao desenvolvimento precoce do trato gastrointestinal. $\mathrm{O}$ fornecimento de dietas específicas para esse período deve levar em consideração não somente a alta qualidade e digestibilidade dos ingredientes, mas também a composição em nutrientes.

A fase pré-inicial representa $17 \%$ do período de vida de um frango de corte e o uso de formulações específicas para pintos de corte nesse período é o reconhecimento da precocidade das linhagens de corte, o que exige reavaliações das práticas nutricionais para acompanhar essas mudanças em benefício da moderna avicultura (Vieira, 2004).

Nutrientes fornecidos nas primeiras horas de vida aos pintinhos, além de facilitarem a capacitação funcional da mucosa intestinal (otimização do aporte enzimático) e o desenvolvimento dos órgãos associados à assimilação dos nutrientes (Uni et al., 1998), diminuem a desidratação pelo jejum, reduzem a mortalidade, aumentam a eficiência na digestão e absorção e estimulam a proliferação de células satélites e sua incorporação às fibras musculares (Vieira, 2004).

Fontes de lipídios que possuem ácidos graxos de cadeia curta e média em sua constituição estão sendo estudados por apresentarem a capacidade de acelerar a reepitelização celular e aumentar o fluxo sanguíneo da mucosa intestinal, atuando como moduladores da proliferação celular.

Ácidos graxos de cadeia curta são mais hidrossolúveis e não são reconvertidos em triglicerídios pelo retículo endoplasmático. Dessa maneira, são absorvidos diretamente pela circulação porta. Isso permite a difusão direta desses ácidos graxos nas células epiteliais para o interior do sangue capilar das vilosidades (Guyton, 1997).

A maior dificuldade aparente na utilização de lipídios pelo pintainho recém-nascido é a imaturidade em sua circulação entero-hepática (Jeanson e Kellog, 1992). Aves nessas condições não respondem com um aumento na capacidade de emulsificação das gorduras ao aumento na presença de gordura no trato digestivo.

A taurina dietética aumenta os ácidos biliares conjugados com a taurina no jejuno das aves aos sete dias e causa efeitos benéficos na eficiência alimentar durante a primeira semana (Anderson et al., 1975; Tufft e Jensen, 1992). De acordo com Huang et al. (2014), a taurina está envolvida com vários eventos fisiológicos, com neuromodulação, osmorregulação, imunomodulação, antioxidação, função cardíaca e da retina, desenvolvimento do cérebro, bem como manutenção do trato gastrointestinal e suas funções.

A glicina é considerada um aminoácido essencial na fase inicial de frangos de corte. Sua suplementação pode aumentar a digestibilidade da gordura da dieta e aumentar a energia metabolizável aparente dela (Reeds e Mersmann, 1991; Ospina-Rojas et al., 2013). Glicina é o principal componente dos sais biliares, constituindo aproximadamente $90 \%$ do total de aminoácidos da bile (Souffrant, 1991).

O objetivo deste estudo foi avaliar o efeito do fornecimento de dietas de transição suplementadas com diferentes fontes de gordura e adicionadas ou não de taurina e glicina sobre o desempenho produtivo e a biometria $\mathrm{e}$ morfometria do intestino delgado de pintos de corte de um a 21 dias de idade.

\section{MATERIAL E MÉTODOS}

O experimento foi conduzido no Aviário Experimental da Universidade Federal do Paraná - Setor Palotina (número do protocolo de aprovação do Comitê de Ética: 13/2010).

Foram utilizados 480 pintos de corte machos de um dia de idade, provenientes de matrizes de 40 semanas de idade da linhagem Cobb. As dietas foram dispostas em um delineamento experimental inteiramente ao acaso, em esquema fatorial 2 x 4, com e sem suplementação de Ltaurina $(0,5 \mathrm{~g} / \mathrm{kg}$ de dieta) e L-glicina $(4 \mathrm{~g} / \mathrm{kg}$ de dieta) e quatro fontes de óleo: dieta basal ( $1 \%$ de óleo de soja), dieta com suplementação de $5 \%$ de óleo de peixe, dieta com suplementação de $5 \%$ de óleo de soja e dieta com suplementação de $5 \%$ de óleo de girassol, totalizando oito tratamentos 
com seis repetições de 10 aves cada. As rações experimentais foram isoenergéticas $(2.960 \mathrm{kcal} / \mathrm{kg})$ e isoproteicas $(22,4 \%)$ e foram fornecidas de zero a quatro dias de idade. Dos quatro aos 21 dias de idade, as aves receberam ração comercial.

As aves foram alojadas em gaiolas durante o período de criação, em uma sala climatizada (arcondicionado e exaustores). Lâmpadas incandescentes foram instaladas em cada gaiola para manter a temperatura ideal para as aves, além do uso de campânula a gás para aquecimento do ambiente. Água e ração foram fornecidas ad libitum durante todo o período experimental, e o programa de luz utilizado foi o de 24 horas de luz durante todo o experimento.

O desempenho zootécnico (peso vivo, consumo de ração e conversão alimentar) foi avaliado ao alojamento e aos quatro, sete e 21 dias de idade. Nessas mesmas datas, foram sacrificadas duas aves por unidade experimental para biometria do intestino e histomorfometria da mucosa do intestino.

Para análise de biometria do intestino, as aves foram pesadas individualmente, e as carcaças dessecadas para remoção do órgão. $O$ peso relativo do intestino foi obtido pela fórmula: peso relativo $=($ peso órgão/peso vivo $) \times 100 . \mathrm{O}$ comprimento do intestino delgado foi tomado para a avaliação da densidade do órgão, expressa em miligramas por centímetro (peso/comprimento ${ }^{-1}$ ). Fragmentos de aproximadamente $5 \mathrm{~cm}$ de comprimento do duodeno, jejuno e íleo foram coletados. As amostras foram fixadas em solução de formol tamponado, incluídas em parafina e submetidas a cortes semisseriados de $5 \mu \mathrm{m}$ de espessura, os quais foram corados pelo método da hematoxilina e eosina (HE). Para o estudo morfométrico, as imagens foram capturadas por meio da microscopia de luz (Olympus BX 50), utilizando-se o sistema analisador de imagens computadorizado (Image Pro-Plus - Versão 5.2 Média Cibernética). Foi mensurada a altura de 20 vilos e a profundidade de 20 criptas de cada repetição por segmento, e desses valores foi obtida a média.

Os resultados obtidos foram submetidos à análise de variância, e as médias comparadas pelo teste de Tukey, ao nível de $5 \%$ de significância, utilizando-se o programa estatístico SAS (SAS Institute Inc., 2002).

\section{RESULTADOS E DISCUSSÃO}

De acordo com a Tab. 1, não houve diferença significativa $(\mathrm{P}>0,05)$ no desempenho produtivo dos pintos entre um e quatro dias de idade, independentemente da adição de lipídios à dieta ou da suplementação de taurina e glicina.

Tabela 1. Desempenho produtivo (CR: consumo de ração, GP: ganho de peso e CA: conversão alimentar) de pintos de corte recebendo dietas de transição suplementadas com diferentes fontes de gordura insaturada e adicionadas ou não de taurina e glicina (TG)

\begin{tabular}{|c|c|c|c|c|c|c|c|c|c|}
\hline & \multicolumn{3}{|c|}{1 a 4 dias de idade } & \multicolumn{3}{|c|}{4 a 7 dias de idade } & \multicolumn{3}{|c|}{1 a 21 dias de idade } \\
\hline & $\mathrm{CR}, \mathrm{g}$ & $\mathrm{GP}, \mathrm{g}$ & $\mathrm{CA}$ & $\mathrm{CR}, \mathrm{g}$ & GP,g & CA & $\mathrm{CR}, \mathrm{g}$ & GP,g & CA \\
\hline Ração basal & 41,52 & 45,77 & 0,912 & 140,23 & 102,46 & 1,354 & 1193,09 & 851,50 & 1,451 \\
\hline Óleo peixe & 40,25 & 45,58 & 0,882 & 145,01 & 100,97 & 1,395 & 1200,46 & 716,75 & 1,510 \\
\hline Óleo soja & 37,52 & 43,65 & 0,863 & 144,23 & 97,12 & 1,403 & 1169,07 & 883,01 & 1,484 \\
\hline Óleo girassol & 40,44 & 43,71 & 0,886 & 147,43 & 99,77 & 1,380 & 1127,76 & 848,00 & 1,376 \\
\hline Com TG & 44,97 & 44,98 & 0,883 & 143,02 & 100,12 & 1,370 & 1157,93 & 779,14 & 1,469 \\
\hline Sem TG & 44,37 & 44,37 & 0,889 & 145,47 & 100,03 & 1,392 & 1187,48 & 810,30 & 1,444 \\
\hline Média & 41,51 & 44,68 & 0,890 & 144,23 & 100,08 & 1,38 & 1172,63 & 814,78 & 1,46 \\
\hline $\mathrm{CV}, \%$ & 14,06 & 5,30 & 13,48 & 9,37 & 6,57 & 7,40 & 7,55 & 8,85 & 11,26 \\
\hline Lipídios & 0,3594 & 0,1257 & 0,7940 & 0,6255 & 0,2523 & 0,7164 & 0,1956 & 0,1287 & 0,2735 \\
\hline TG & 0,9847 & 0,4619 & 0,8633 & 0,5337 & 0,9652 & 0,4573 & 0,2651 & 0,1329 & 0,6320 \\
\hline Interação & 0,3616 & 0,3859 & 0,0940 & 0,6495 & 0,7967 & 0,2350 & 0,4217 & 0,4674 & 0,3972 \\
\hline
\end{tabular}

Aos quatro dias, não houve diferença significativa $(\mathrm{P}>0,05)$ na biometria intestinal para nenhum tratamento (Tab. 2). Entretanto, aos sete dias de idade, houve efeito significativo $(\mathrm{P}<0,05)$ apenas da fonte de lipídio utilizada sobre o comprimento do intestino. Aves 
suplementadas com dietas acrescidas de óleo de peixe apresentaram maior comprimento do intestino quando comparadas às aves da dieta controle e da dieta com óleo de soja.

Não houve efeito significativo $(\mathrm{P}>0,05)$ da suplementação de glicina e taurina à dieta das aves para a biometria do intestino delgado. Em contraste com os resultados aqui apresentados, Huang et al. (2014) encontraram um retardamento do desenvolvimento intestinal, mostrando redução do peso e menor comprimento do intestino aos 21 dias de idade, em aves suplementadas com níveis de taurina na dieta de até $2 \mathrm{~g} / \mathrm{kg}$.

Tabela 2. Biometria do intestino delgado de pintos de corte recebendo dietas de transição suplementadas com diferentes fontes de gordura insaturada e adicionadas ou não de taurina e glicina (TG)

\begin{tabular}{lccccccccc} 
& \multicolumn{3}{c}{4 dias de idade } & \multicolumn{3}{c}{7 dias de idade } & \multicolumn{3}{c}{21 dias de idade } \\
& $\mathrm{cm}$ & $\%$ & $\mathrm{mg} / \mathrm{cm}^{-1}$ & $\mathrm{~cm}$ & $\%$ & $\mathrm{mg} \mathrm{cm}^{-1}$ & $\mathrm{~cm}$ & $\%$ & $\mathrm{mg} \mathrm{cm}^{-1}$ \\
\cline { 2 - 10 } Ração basal & 76,92 & 12,37 & 79,24 & $99,08^{\mathrm{b}}$ & 12,64 & 204,15 & 126,17 & 5,58 & 568,68 \\
Óleo peixe & 75,75 & 12,91 & 83,26 & $103,92^{\mathrm{a}}$ & 12,73 & 218,65 & 135,25 & 6,02 & 628,35 \\
Óleo soja & 75,78 & 12,90 & 84,74 & $98,08^{\mathrm{b}}$ & 11,73 & 202,18 & 117,75 & 5,28 & 475,30 \\
Óleo girassol & 76,58 & 12,88 & 83,01 & $100,52^{\mathrm{ab}}$ & 12,55 & 211,70 & 124,75 & 5,61 & 553,60 \\
& & & & & & & & & \\
Com TG & 75,43 & 12,59 & 80,41 & 101,44 & 12,38 & 210,68 & 124,42 & 5,59 & 553,78 \\
Sem TG & 76,99 & 12,94 & 84,76 & 99,34 & 12,44 & 207,42 & 127,54 & 5,67 & 559,19 \\
Média & 76,21 & 12,68 & 81,98 & 100,40 & 12,28 & 206,89 & 125,98 & 2,91 & 556,48 \\
CV, \% & 8,28 & 8,78 & 18,44 & 7,76 & 11,68 & 19,04 & 11,79 & 16,54 & 35,00 \\
\hline Lipídios & 0,7713 & 0,1112 & 0,4615 & 0,0596 & 0,0767 & 0,4929 & 0,0614 & 0,2977 & 0,3026 \\
TG & 0,1413 & 0,0674 & 0,0869 & 0,1933 & 0,8587 & 0,6965 & 0,4704 & 0,6968 & 0,9237 \\
Interação & 0,7886 & 0,5787 & 0,7496 & 0,7951 & 0,6682 & 0,5605 & 0,7720 & 0,5040 & 0,5080 \\
\hline
\end{tabular}

Houve interação significativa $(\mathrm{P}<0,05)$ entre a fonte de lipídios e a suplementação de taurina e glicina para a profundidade de cripta do duodeno das aves com quatro dias de idade (Tab. 3). Aves que receberam a ração basal e a ração com óleo de girassol, suplementadas com os aminoácidos, apresentaram menor profundidade de cripta em comparação com as dietas isentas de suplementação de glicina e taurina (Tab. 4).

Aves suplementadas com óleo de peixe apresentaram uma maior relação vilo:cripta $(\mathrm{P}<0,05)$ comparando-se com as outras fontes de suplementação aos quatro dias de idade. A suplementação com glicina e taurina resultou em maior relação vilo:cripta, independentemente da inclusão das fontes de lipídios. Essa maior relação vilo:cripta pode ser resultado de uma maior atividade proliferativa das células da mucosa intestinal pelo possível efeito trófico dos aminoácidos suplementados, refletindo em aumento da altura da vilosidade. Essa característica é muito importante para o aumento da capacidade absortiva do trato gastrointestinal da ave e, consequentemente, para o desempenho dela.
Aos quatro dias de idade, as aves suplementadas com os aminoácidos glicina e taurina apresentaram uma menor profundidade de cripta do jejuno em relação às aves não suplementadas com os aminoácidos. Segundo Geyra et al. (2001), a menor profundidade de cripta pode ser decorrente da menor taxa de proliferação celular, indicando que não há necessidade de aumento na taxa de regeneração da mucosa intestinal nos casos em que o vilo apresenta integridade.

Aos sete dias de idade, as aves que receberam a dieta pós-eclosão de um a quatro dias de idade suplementada com óleo de peixe apresentaram uma maior profundidade de cripta $(<0,05)$ e as aves que receberam óleo de soja apresentaram uma menor profundidade. A partir do quinto dia de idade, todas as aves passaram a receber uma dieta com óleo de soja. Assim, é possível relacionar a maior profundidade de cripta encontrada nas aves que receberam óleo de peixe na dieta, com a mudança do perfil lipídico da dieta. A partir do sétimo dia, após a adaptação à troca da dieta, não se observaram mais diferenças significativas. 


\section{Fernandes et al.}

Tabela 3. Morfometria do intestino delgado de pintos de corte aos quatro, sete e 21 dias de idade recebendo dietas pós-eclosão suplementadas com diferentes fontes de gordura insaturada e adicionadas ou não de taurina e glicina (TG)

\begin{tabular}{|c|c|c|c|c|c|c|c|c|c|c|c|c|}
\hline & \multicolumn{4}{|c|}{ Duodeno } & \multicolumn{4}{|c|}{ Jejuno } & \multicolumn{4}{|c|}{ Íleo } \\
\hline & Vilo, $\mu \mathrm{m}$ & Cripta, $\mu \mathrm{m}$ & $\mathrm{V}: \mathrm{C}$ & Área, $\mu \mathrm{m}^{2}$ & Vilo, $\mu \mathrm{m}$ & Cripta, $\mu \mathrm{m}$ & $\mathrm{V}: \mathrm{C}$ & Área, $\mu \mathrm{m}^{2}$ & Vilo, $\mu \mathrm{m}$ & Cripta, $\mu \mathrm{m}$ & $\mathrm{V}: \mathrm{C}$ & Área, $\mu \mathrm{m}^{2}$ \\
\hline & \multicolumn{12}{|c|}{4 dias } \\
\hline Ração basal & 891,20 & 103,16 & $8,83^{b}$ & 8,82 & 393,83 & 78,39 & 5,12 & 4,67 & 360,06 & 68,24 & 5,37 & 4,39 \\
\hline Óleo de peixe & 962,42 & 99,13 & $9,95^{\mathrm{a}}$ & 9,47 & 397,34 & 72,61 & 5,54 & 4,80 & 383,63 & 66,89 & 5,82 & 4,86 \\
\hline Óleo de soja & 948,27 & 103,33 & $9,58^{\mathrm{ab}}$ & 9,37 & 417,94 & 75,55 & 5,58 & 4,90 & 372,29 & 65,77 & 5,70 & 4,47 \\
\hline Óleo de girassol & 916,11 & 102,45 & $9,18^{\mathrm{ab}}$ & 9,22 & 387,09 & 75,28 & 5,18 & 4,82 & 366,12 & 64,85 & 5,69 & 4,52 \\
\hline Sem TG & 934,38 & 105,58 & $9,05^{b}$ & 9,34 & 409,32 & $78,19^{\mathrm{a}}$ & 5,31 & 4,86 & 379,02 & 68,27 & 5,62 & 4,53 \\
\hline Com TG & 917,27 & 98,57 & $9,62^{\mathrm{a}}$ & 9,03 & 389,54 & $72,65^{b}$ & 5,41 & 4,74 & 361,40 & 64,43 & 5,68 & 4,60 \\
\hline Média & 925,95 & 102,13 & 9,33 & 9,19 & 399,31 & 75,39 & 5,36 & 4,80 & 370,67 & 66,45 & 5,65 & 4,56 \\
\hline $\mathrm{CV}, \%$ & 9,42 & 9,34 & 13,23 & 11,10 & 19,05 & 9,59 & 15,00 & 22,47 & 15,37 & 9,52 & 13,65 & 17,55 \\
\hline Lipídios & 0,0809 & 0,4244 & 0,0353 & 0,2640 & 0,6118 & 0,1140 & 0,1422 & 0,9357 & 0,6177 & 0,5040 & 0,3348 & 0,2904 \\
\hline TG & 0,7321 & 0,0084 & 0,0363 & 0,3127 & 0,2726 & 0,0008 & 0,4854 & 0,6265 & 0,1794 & 0,0089 & 0,7821 & 0,7470 \\
\hline \multirow[t]{2}{*}{ Interação } & 0,3876 & 0,0459 & 0,8483 & 0,7506 & 0,8886 & 0,3995 & 0,4701 & 0,4522 & 0,7825 & 0,3937 & 0,3536 & 0,8235 \\
\hline & \multicolumn{12}{|c|}{7 dias } \\
\hline Ração basal & 1067,04 & 167,88 & 6,47 & 11,45 & 487,77 & $122,98^{\text {ab }}$ & 3,78 & 6,24 & 374,20 & 119,18 & 3,19 & 5,07 \\
\hline Óleo de peixe & 1215,97 & 178,84 & 6,97 & 13,92 & 481,45 & $135,74^{\mathrm{a}}$ & 3,73 & 6,07 & 443,92 & 137,59 & 3,33 & 6,82 \\
\hline Óleo de soja & 1162,92 & 169,79 & 6,45 & 10,86 & 424,90 & $104,79^{\mathrm{b}}$ & 4,29 & 6,53 & 393,25 & 107,39 & 3,61 & 5,41 \\
\hline Óleo de girassol & 1042,32 & 163,43 & 6,65 & 11,14 & 473,88 & $113,60^{\mathrm{ab}}$ & 4,04 & 6,32 & 414,02 & 130,34 & 3,20 & 5,82 \\
\hline Sem TG & 1118,47 & 170,32 & 6,49 & 12,52 & 498,38 & 125,23 & 4,07 & 6,44 & 392,99 & 118,26 & 3,40 & $4,96^{b}$ \\
\hline Com TG & 1122,63 & 168,61 & 6,81 & 11,49 & 443,65 & 114,66 & 3,85 & 6,14 & 419,32 & 131,08 & 3,23 & $6,58^{\mathrm{a}}$ \\
\hline Média & 1120,66 & 169,43 & 6,65 & 11,99 & 468,16 & 119,59 & 3,95 & 6,27 & 406,43 & 124,67 & 3,31 & 5,74 \\
\hline $\mathrm{CV}, \%$ & 23,25 & 19,78 & 26,65 & 27,74 & 18,97 & 19,98 & 19,65 & 21,34 & 20,24 & 20,83 & 12,92 & 43,96 \\
\hline Lipídios & 0,3996 & 0,7739 & 0,8205 & 0,2917 & 0,6403 & 0,0128 & 0,1376 & 0,7010 & 0,2602 & 0,0846 & 0,1304 & 0,3404 \\
\hline & 0,6950 & 0,8242 & 0,3740 & 0,6123 & 0,0901 & 0,1149 & 0,1667 & 0,2380 & 0,4231 & 0,1935 & 0,2146 & 0,0433 \\
\hline \multirow[t]{2}{*}{ Interação } & \multirow{2}{*}{\multicolumn{12}{|c|}{21 dias }} \\
\hline & & & & & & & & & & & & \\
\hline Ração basal & 1232,74 & 137,72 & 9,17 & 15,76 & 1062,49 & 99,84 & 10,40 & 16,17 & 687,92 & 102,25 & 6,92 & 10,47 \\
\hline Óleo de peixe & 1318,99 & 131,65 & 10,16 & 14,70 & 967,92 & 94,35 & 10,59 & 14,23 & 718,66 & 134,85 & 6,75 & 11,16 \\
\hline Óleo de soja & 1179,21 & 114,86 & 10,38 & 15,45 & 876,41 & 85,49 & 10,97 & 13,41 & 649,77 & 99,09 & 6,73 & 9,59 \\
\hline Óleo de girassol & 1320,85 & 126,91 & 10,95 & 13,14 & 823,84 & 83,56 & 9,87 & 11,89 & 719,36 & 91,83 & 7,95 & 11,13 \\
\hline Sem TG & 1272,27 & 127,86 & 10,20 & 15,64 & 957,45 & 92,01 & 10,41 & 13,82 & 720,25 & 117,56 & 7,16 & 10,50 \\
\hline Com TG & 1264,39 & $\begin{array}{l}129,24 \\
124\end{array}$ & $\begin{array}{l}10,14 \\
10,14\end{array}$ & $\begin{array}{l}13,98 \\
13,98\end{array}$ & 908,20 & 90,13 & $\begin{array}{l}10,47 \\
10,47\end{array}$ & $\begin{array}{l}14,15 \\
14,15\end{array}$ & 663,33 & 97,57 & 6,96 & $\begin{array}{l}10,61 \\
10,10\end{array}$ \\
\hline Média & 1268,04 & 128,64 & 10,16 & 14,75 & 934,63 & 91,12 & 10,43 & 13,97 & 692,45 & 107,79 & 7,06 & 10,56 \\
\hline $\mathrm{CV}, \%$ & 26,32 & 22,61 & 25,66 & 35,08 & 32,70 & 20,65 & 33,42 & 39,91 & 22,02 & 48,62 & 22,49 & 26,71 \\
\hline Lipídios & 0,6110 & 0,3989 & 0,3697 & 0,7459 & 0,3459 & 0,1329 & 0,9120 & 0,4030 & 0,6189 & 0,2255 & 0,2767 & 0,5024 \\
\hline & 0,8573 & 0,5335 & 0,8485 & 0,3847 & 0,9708 & 0,7948 & 0,8372 & 0,4622 & 0,2436 & 0,2475 & 0,6161 & 0,8752 \\
\hline Interação & 0,0369 & 0,6077 & 0,0099 & 0,4168 & 0,2190 & 0,2085 & 0,4433 & 0,0902 & 0,3885 & 0,2737 & 0,4163 & 0,7888 \\
\hline
\end{tabular}

Tabela 4. Desdobramento das interações da morfometria do duodeno de pintos de corte aos quatro, sete e 21 dias recebendo dietas pós-eclosão suplementadas com diferentes fontes de gordura insaturada e adicionadas ou não de glicina e taurina (TG)

\begin{tabular}{|c|c|c|c|}
\hline & \multicolumn{3}{|c|}{ Cripta, $\mu \mathrm{m}-4$ dias } \\
\hline & Sem TG & Com TG & Valor de P \\
\hline Ração basal & $110,52^{\mathrm{aA}}$ & $97,14^{\mathrm{bA}}$ & 0,0002 \\
\hline Óleo de peixe & $102,73^{\mathrm{aA}}$ & $95,01^{\mathrm{aA}}$ & 0,1003 \\
\hline Óleo de soja & $101,24^{\mathrm{aA}}$ & $106,46^{\mathrm{aA}}$ & 0,4730 \\
\hline Óleo de girasol & $107,50^{\mathrm{aA}}$ & $97,91^{\mathrm{bA}}$ & 0,0439 \\
\hline \multirow[t]{2}{*}{ Valor de $\mathrm{P}$} & 0,0756 & 0,2702 & \\
\hline & \multicolumn{3}{|c|}{ Vilo, $\mu \mathrm{m}-21$ dias } \\
\hline Ração basal & $1449,68^{\mathrm{aA}}$ & $964,39^{\mathrm{bB}}$ & 0,0047 \\
\hline Óleo de peixe & $1189,51^{\mathrm{aAB}}$ & $1411,49^{\mathrm{aA}}$ & 0,3125 \\
\hline Óleo de soja & $941,24^{\mathrm{bB}}$ & $1322,00^{\mathrm{aA}}$ & 0,0019 \\
\hline Óleo de girasol & $1340,90^{\mathrm{aAB}}$ & $1300,75^{\mathrm{aA}}$ & 0,8308 \\
\hline \multirow[t]{2}{*}{ Valor de P } & 0,0228 & 0,0200 & \\
\hline & \multicolumn{3}{|c|}{ Relação vilo:cripta, $\mu \mathrm{m}$ - 21 dias } \\
\hline Ração basal & $3,2897^{\mathrm{aA}}$ & $2,5590^{\mathrm{bB}}$ & 0,0492 \\
\hline Óleo de peixe & $2,8510^{\mathrm{aB}}$ & $3,3735^{\mathrm{aA}}$ & 0,0525 \\
\hline Óleo de soja & $2,9162^{\mathrm{aB}}$ & $3,3265^{\mathrm{aA}}$ & 0,1209 \\
\hline Óleo de girasol & $3,4746^{\mathrm{aA}}$ & $3,1206^{\mathrm{aA}}$ & 0,2992 \\
\hline Valor de $\mathrm{P}$ & 0,0347 & 0,0122 & \\
\hline
\end{tabular}

Médias seguidas de letras distintas maiúsculas na coluna diferem entre si pelo teste de Tukey; médias seguidas de letras minúsculas distintas na linha diferem entre si pelo teste Tukey.

A área de absorção do íleo aos sete dias foi maior nas aves suplementadas com os aminoácidos. Esse efeito pode estar relacionado com o possível efeito trófico dos aminoácidos glicina e taurina nos primeiros dias de vida. 
Martinez et al. (2012) atribuíram à suplementação de glutamina, outro aminoácido considerado trófico para a mucosa intestinal, a melhora na integridade intestinal de pintos na fase inicial de vida.

Segundo Pelicano et al. (2003), na presença de nutrientes, a capacidade absortiva do segmento intestinal será diretamente proporcional ao número de vilosidades ali presentes, ao tamanho dos vilos e à área de superfície disponível para a absorção.

Houve interação significativa $(\mathrm{P}<0,05)$ aos 21 dias de idade para o segmento do duodeno para altura de vilo e relação vilo:cripta entre as diferentes fontes de lipídios na dieta inicial e a suplementação de glicina e taurina (Tab. 4). Para altura de vilo, ao se desdobrar a interação, observou-se que as três diferentes fontes de óleo fornecidas resultaram em maior altura dos vilos quando os aminoácidos foram adicionados às dietas. A dieta suplementada com óleo de soja sem os aminoácidos resultou no menor vilo, entretanto, quando os aminoácidos foram incluídos, isso resultou na maior $(\mathrm{P}<0,05)$ altura de vilo. Considerando que o óleo de soja é uma fonte usual de suplementação na dieta de frangos de corte, a inclusão de glicina e taurina nas rações proporcionaria uma melhor área para absorção dos nutrientes e aproveitamento deles pelo animal.

Como os processos de absorção de nutrientes são totalmente dependentes dos mecanismos que ocorrem na mucosa intestinal, a manipulação da dieta pós-eclosão pode trazer melhorias no desempenho e, consequentemente, na eficiência energética do intestino, principalmente em situações de desafios entéricos. Um epitélio intestinal íntegro age como uma barreira natural contra bactérias patogênicas e substâncias tóxicas presentes na luz intestinal.

Para a relação vilo:cripta aos 21 dias de idade, observou-se maior relação vilo:cripta nas dietas acrescidas de óleo quando suplementadas com glicina e taurina em comparação a dietas sem a suplementação desses aminoácidos. A glicina da dieta, além da síntese proteica, também é utilizada para a formação de DNA, RNA, creatina e ácido úrico (Ngo et al., 1977). Já a taurina está envolvida na proliferação celular, além da atuação em vários outros eventos fisiológicos que garantem a funcionalidade do organismo (Huang et al., 2014). Assim, a soma desses efeitos explica a maior relação vilo:cripta encontrada, garantindo uma melhor condição intestinal para essas aves.

De acordo com os resultados obtidos neste experimento, dietas de transição, fornecidas entre um e quatro dias de idade e elaboradas com inclusões de $5 \%$ de lipídios, independentemente da fonte, parecem beneficiar o desenvolvimento intestinal de frangos de corte. Vistos os benefícios das dietas acrescidas de $5 \%$ de fontes lipídicas, é necessário estudar um maior tempo de fornecimento dessa dieta, talvez durante a primeira semana de vida dos pintainhos, e seus impactos em qualidade intestinal e desempenho dos animais, bem como a suplementação nessa primeira semana com os aminoácidos glicina e taurina, que darão suporte para a digestão desse aumento dos lipídios na dieta e poderão, também, aumentar a proliferação celular, proporcionando uma melhor estrutura intestinal.

\section{CONCLUSÃO}

O fornecimento de dietas de transição, fornecidas entre um e quatro dias de idade, elaboradas com inclusões de óleo de soja, de girassol ou de peixe e suplementadas com glicina e taurina, não influenciou o desempenho produtivo de um a 21 dias.

A suplementação das dietas com glicina e taurina, independentemente da fonte de óleo, alterou a morfologia da mucosa intestinal, sobretudo do duodeno, resultando em maior comprimento do vilo e da relação vilo:cripta.

\section{REFERÊNCIAS}

ANDERSON, J.O; WARNICK, R.E.; DALAI, R.K. Replacing dietary methionine and cystine in chick diets with sulfate or other sulfur compounds. Poult. Sci., v.54, p.1122-1128, 1975.

GEYRA, A.; UNI, Z.; SKLAN, D. The effect of fasting at different ages on growth and tissue dynamics in the small intestine of the young chick. Br. J. Nutr., v.86, p.53-61, 2001.

GUYTON, A.C. Digestão e absorção no tubo gastrintestinal. In: ___ Tratado de fisiologia médica. 9.ed. Rio de Janeiro: Guanabara Koogan, 1997. p.633-641. 
HUANG, C.; GUO, Y.; YUAN, J. Dietary taurine impairs intestinal growth and mucosal structure of broiler chickens by increasing toxic bile acid concentrations in the intestine. Poult. Sci., v.93, p.1475-1483, 2014.

JEANSON, S.E.; KELLOG, T.F. Ontogeny of taurocholate accumulation in the terminal ileal mucosal cells of young chicks. Poult. Sci., v.71, p.367-372, 1992.

MARTINEZ, K.L.A.; LEANDRO, N.S.M.; CAFÉ, M.B. et al. Suplementação de glutamina em dietas elaboradas com ingredientes de origem vegetal e animal para pintos de corte. Arq. Bras. Med. Vet. Zootec., v.64, p.1707-1716, 2012.

NGO, A.; COON, C.N.; BEECHER, R. Dietary glycine requirements for growth and cellular development in chicks. J. Nutr., v.107, p.18001808, 1977.

OSPINA-ROJAS, I.C.; MURAKAMI, A.E.; OLIVEIRA, C.A.; GUERRA, A.F. Supplemental glycine and threonine effects on performance, intestinal mucosa development, and nutrient utilization of growing broiler chickens. Poult. Sci., v.92, p.2724-273, 2013.

PELICANO, E.R.L.; SOUZA, P.A.; SOUZA, H.B.A. et al. Morfometria e ultra-estrutura da mucosa intestinal de frangos de corte alimentados com dietas contendo diferentes probióticos. Rev. Port. Cienc. Vet., v.98, p.125134, 2003
REEDS, P.J.; MERSMANN, H.J. Protein and energy requirements of animals treated with beta-adrenergic agonists: a discussion. J. Anim. Sci., v.69, p.1532-1550, 1991.

SOUFFRANT, W.B. Endogenous nitrogen losses during digestion in pigs. In: INTERNATIONAL SYMPOSIUM ON DIGESTIVE PHYSIOLOGY IN PIGS, 5., 1991, Wageningen. Proceedings... Wageningen, Netherlands: Centre for Agricultural publishing and Documentation, 1991. p.147-166.

SAS Institute Inc. 2002. Software and services: system for Windows, version 8.0 software Cary.

TUFFT, L.S.; JENSEN, L.S. Influence of dietary taurine on performance and fat retention in broilers and turkey poults fed varying levels of fat. Poult. Sci., v.71, p.880-885, 1992.

UNI, Z.; GANOT, S.; SKLAN, D. Posthatch development of mucosal function in the broiler small intestine. Poult. Sci., v.77, p.75-82, 1998.

VIEIRA, S.L. Digestão e utilização de nutrientes após a eclosão de frangos de corte. In: SIMPÓSIO BRASIL SUL DE AVICULTURA, 5., 2004, Chapecó. Anais... Chapecó: Embrapa Suínos e Aves, 2004. p.26-41. 